Published in final edited form as:

Endocrinol Metab Clin North Am. 2015 June ; 44(2): 275-296. doi:10.1016/j.ecl.2015.02.002.

\title{
Adrenal Steroidogenesis and Congenital Adrenal Hyperplasia
}

\author{
Adina F. Turcu and Richard J. Auchus* \\ Division of Metabolism, Endocrinology, \& Diabetes, Department of Internal Medicine and \\ Department of Pharmacology, University of Michigan, Room 5560A, 1150 West Medical Center \\ Drive, Ann Arbor, Ml 48109, United States
}

\section{Synopsis}

Adrenal steroidogenesis is a dynamic process, reliant on de novo synthesis from cholesterol, under the stimulation of ACTH and other regulators. The syntheses of mineralocorticoids,

glucocorticoids and adrenal androgens occur in separate adrenal cortical zones, each expressing specific enzymes. Congenital adrenal hyperplasia (CAH) encompasses a group of autosomal recessive enzymatic defects in cortisol biosynthesis. 21-hydroxylase (21OHD) deficiency accounts for over $90 \%$ of CAH cases and when milder or nonclassic forms are included, 21OHD is one of the most common genetic diseases. This review discusses in detail the epidemiology, genetics, diagnostic, clinical aspects and management of 21OHD.

\section{Keywords}

steroidogenesis; congenital adrenal hyperplasia; 21-hydroxylase; androgen; steroid hydroxylase; adrenal insufficiency; ambiguous genitalia; disorder of sex development

\section{Adrenal steroidogenesis}

Adrenal steroidogenesis is a dynamic process, reliant on de novo synthesis, with no presynthesized hormones stored for immediate release. Cholesterol is the common precursor for all steroids and is efficiently converted along a series of steps to the final product. To initiate steroidogenesis, cholesterol is mobilized from a pool in the outer mitochondrial membrane $(\mathrm{OMM})^{1}$, which is replenished from cytosolic storage droplets of cholesterol esters. The steroidogenic acute regulatory (StAR) protein enables cholesterol transfer from the OMM to the inner mitochondrial membrane (IMM) ${ }^{2}$, where the side-chain cleavage enzyme (CYP11A1, P450scc) catalyzes the first and rate-limiting step of steroidogenesis: the conversion of cholesterol to pregnenolone ${ }^{1,3}$ (Figure 1A).

\section{A. Aldosterone biosynthesis}

Mineralocorticoid synthesis occurs in the zona glomerulosa (ZG), and requires the subsequent action of three enzymes: 1. 33-hydroxysteroid dehydrogenase type 2(HSD3B2), which performs the irreversible conversion of the hydroxyl group to a keto group on carbon 3 and simultaneous isomerization of the double bond from the $\Delta^{5}$ to the $\Delta^{4}$ position ${ }^{4} ; 2.21$ -

\footnotetext{
*Corresponding author: Tel 734-764-7764, FAX 734-936-6684, rauchus@ @med.umich.edu.
} 
hydroxylase (CYP21A2, P450c21), which converts progesterone into 11-

deoxycosticosterone; 3 . aldosterone synthase (CYP11B2, P450c11AS), which catalyzes the final three steps of aldosterone synthesis: 11 $\beta$-hydroxylation, 18-hydroxylation, and 18methyl oxidation. The 18-aldehyde group, from which the name "aldosterone" derives, forms an intramolecular cyclic hemiacetal using the 11ß-hydroxyl group, with loss of water.

The ZG is optimized for aldosterone synthesis: it is the only zone that has CYP11B2 and, in contrast, has little 17a-hydroxylase/17,20-lyase (CYP17A1, P450c17), an enzyme which directs steroids substrates towards cortisol and androgens synthesis ${ }^{5}$ (Figure 1B). Angiotensin 2 and high extracellular potassium are the main stimulators of aldosterone synthesis, via increased intracellular calcium ${ }^{6}$.

\section{B. Cortisol biosynthesis}

The glucocorticoid cortisol is synthesized in the zona fasciculata $(\mathrm{ZF})$ under the regulation of adrenocorticotropin (ACTH). CYP17A1 catalyzes the 17a-hydroxylation of pregnenolone and progesterone with roughly equal efficiency, and this reaction leads to cortisol production. In addition, CYP17A1 subsequently cleaves the C17-C20 bond of 17hydroxypregnenolone and to a much lesser degree of 17-hydroxyprogesterone (17OHP), which leads to 19-carbon $\left(\mathrm{C}_{19}\right)$ steroids (Figure 1A). Both reactions occur in a single active site, but with different regulation, as described below. With the activities of HDS3B2 and CYP21A2, which perform reactions similar to those on the mineralocorticoid pathway, 17hydroxysteroids are converted to 11-deoxycortisol. Lastly, 11 $\beta$-hydroxylase (CYP11B1, P450c11 $\beta$ ), an enzyme closely related to CYP11B2, completes the synthesis of cortisol. In rodents and many small animals, the ZF lacks CYP17A1. Consequently, nascent progesterone is 21 - and $11 \beta$-hydroxylated to yield corticosterone, which is the dominant glucocorticoid in these species, but it is ordinarily a minor product of the human adrenal.

\section{Adrenal androgen biosynthesis}

Adrenal $\mathrm{C}_{19}$ steroids are synthesized in the zona reticularis (ZR). Dehydroepiandrosterone (DHEA) and its sulfate (DHEAS) are the two most abundant adrenal steroids. CYP17A1 is the only enzyme required for DHEA synthesis from pregnenolone and for androstenedione (AD) synthesis from progesterone. While CYP17A1 is present in both ZF and ZR, its 17,20lyase reaction is enhanced approximately 10 times by the cofactor cytochrome $b_{5}$ (CYB5A), which is absent in the $\mathrm{ZF}^{7}$ (Figure 1B). Sulfotransferase SULT2A1 conjugates DHEA to DHEAS, a steroid with an important role in the regulation of adrenal androgen synthesis ${ }^{8}$. The adrenal synthesizes small amounts of testosterone, by the action of 17ß-hydroxysteroid dehydrogenase type 5 (17ßHSD5, AKR1C3) on AD (Figure 1A).

$\mathrm{ACTH}$ is the primary stimulus of steroidogenesis in the $\mathrm{ZR}$ and is required for $\mathrm{ZR}$ development ${ }^{9,10}$. Additional growth factors have been postulated to regulate adrenal androgen synthesis and to control the development of the $\mathrm{ZR}$, but these remain poorly understood. The ZR resembles the fetal adrenal, which provides the $\mathrm{C}_{19}$ substrate for estrogen synthesis during pregnancy but involutes at birth. The ZR is only few cells thick at birth but expands during childhood, leading to a rise in circulating DHEAS and the phenomenon of adrenarche, which manifests as the development of axillary and pubic hair. 
ZR function and serum DHEAS peak about age 25 and then gradually decline, falling to childhood values in the seventh or eighth decade of life.

\section{Congenital adrenal hyperplasia}

\section{A. Definition and classification}

Congenital adrenal hyperplasia (CAH) refers to a group of inherited enzymatic defects in cortisol biosynthesis. Impaired cortisol production relieves negative feedback to the hypothalamus and the pituitary gland, which in response amplify the secretion of corticotropin-releasing hormone (CRH) and ACTH, respectively, resulting in hyperplasia of the adrenal cortex. The spectrum of enzymatic deficiencies ranges from mild to complete and from a single activity to several activities. Steroid 21-hydroxylase deficiency (21OHD) accounts for over $90 \%$ of CAH cases $^{11}$. Conventionally, 21OHD is dichotomized into classic and nonclassic forms, based on the presence or absence of cortisol insufficiency. The classic forms of $21 \mathrm{OHD}$ are further grouped into "salt wasting" and "simple virilizing" subtypes, depending on whether or not mineralocorticoid synthesis is sufficiently impaired to cause spontaneous hypotensive crises in the infant.

Other forms of $\mathrm{CAH}$ are summarized in Table 1. For additional information, the reader is directed towards recent reviews and chapters on deficiencies in CYP17A $1{ }^{12}$, CYP11B $1{ }^{13}$, HSD3B2 ${ }^{14}$, lipoid $\mathrm{CAH}^{15}$, cholesterol side-cleavage enzyme (P450scc) ${ }^{16}$ and $\mathrm{P} 450$ oxidoreductase (POR) ${ }^{17}$. This review will further expand the discussion of $210 H D$.

\section{B. Epidemiology}

Classic 21OHD occurs in 1 of 16,000 live births worldwide ${ }^{18}$. Nonclassic $210 H D$ is much more frequent, occurring in approximately 1 of 1,000 Caucasians and more commonly in certain ethnic groups, such as Ashkenazi Jews (1:27), Hispanics (1:53), Yugoslavs (1:62) and Italians $(1: 300)^{19}$. The reason why classic $21 \mathrm{OHD}$ has a similar prevalence throughout most of the world is related to the structure of the RCCX locus containing the RP protein kinase, C4, CYP21, and tenascin X genes, including the CYP21A2 gene encoding the CYP21A2 enzyme.

\section{Genetics}

All forms of $\mathrm{CAH}$ are inherited in a monogenic, autosomal-recessive pattern. Human 21hydroxylase is encoded by CYP21A2 gene, on chromosome 6p21.3, within the HLA major histocompatibility complex and adjacent to the genes for the fourth component of complement ${ }^{20-22}$. Only $30 \mathrm{~kb}$ away resides the non-functional CYP21A1P pseudogene, which encodes a truncated, inactive enzyme. Both CYP21A2 and CYP21A1P contain 10 exons, and the 2 genes share $98 \%$ homology. The majority of mutant $21 \mathrm{OHD}$ alleles result from intergenic recombinations and gene conversion events between the two CYP21A genes $^{23}$. Complete deletions, large gene conversions, and non-sense or frame-shift mutations that completely ablate 21-hydroxylase activity typically result in salt-wasting forms of CAH. Mutations resulting in even 1-2\% residual enzyme activity allow sufficient aldosterone production and lead to simple virilizing forms of CAH. Nonclassic 21OHD patients retain $20-60 \%$ of the enzyme activity and do not have adrenal insufficiency. Nonclassic 21OHD 
patients may be either compound heterozygotes (with one classic allele and one nonclassic allele) or heterozygotes with two nonclassic alleles. While the most severe and mildest forms of the disease tend to maintain some genotype-phenotype correlation, the intermediate forms are often poorly linked with specific gene defects, suggesting other contributors (genetic or environmental) to the phenotypical expression ${ }^{23}$.

\section{Biochemistry of 210HD}

As a result of 21-hydroxylase dysfunction, upstream steroid precursors accumulate and are diverted towards accessible pathways to form potent androgens (Figure 2). Elevations of 17OHP, the main substrate of CYP21A2, are a hallmark of 21OHD, and 17OHP has traditionally been used for both diagnosis and monitoring of the disease. Additionally, the CYP21 A2 blockage promotes the build-up of other $\mathrm{C}_{21}$ steroids. Human CYP17A1 hydroxylates pregnenolone and progesterone in position 17 with equal efficiencies, but also 16 a-hydroxylates up to $30 \%$ of progesterone ${ }^{24}$. In the normal pathways to aldosterone and cortisol, progesterone and 17OHP are first hydroxylated at position 21 by CYP21A2, and subsequently at other positions. In 21OHD, progesterone and 17OHP accumulate and are substrates for CYP11B1, leading to 11 -hydroxyprogesterone (11OHP) and 21deoxycortisol (21dF), respectively.

The excess 17OHP resulting from CYP21A2 deficiency is diverted through the pathways left accessible, to form potent androgens, such as testosterone and 5a-dihydrotestosterone (DHT). CYP17A1 mediates the conversion of 17-hydroxypregnenolone to DHEA ( $\Delta^{5}$ pathway) and of 17OHP to $\mathrm{AD}$ ( $\Delta^{4}$ pathway). The catalytic efficiency of the human 17,20lyase, however, is approximately 100 times greater for the $\Delta^{5}$ reaction, as compared with the $\Delta^{4}$ reaction ${ }^{25}$, explaining the enormous $17 \mathrm{OHP}$ accumulation in 21OHD. In patients with 21OHD, significant AD synthesis might still occur via the $\Delta^{4}$ pathway due to very high intra-adrenal 17OHP.

More recently, a third potential fate of 17OHP has been suggested in patients with 21OHD: androgen synthesis via the "backdoor pathway" (Figure 2). This pathway was initially described a decade ago in tammar wallabies, whose testes produce $5 a$-androstane-3a,17 $\beta$ diol (5aAdiol) rather than testosterone ${ }^{26}$. The $17 \mathrm{OHP}$ is first $5 \mathrm{a}-$, then $3 \mathrm{a}$-reduced, and only subsequently undergoes 17,20-lyase cleavage, to form androsterone. After 17 $\beta$-reduction to 5aAdiol, circulating 5aAdiol is 3a-oxidized to produce DHT in target tissues such as genital skin and prostate, thus bypassing the conventional androgens $\mathrm{AD}$ and testosterone as intermediates. This pathway might contribute to the virilization of female fetuses with $\mathrm{CAH}^{27}$. Kamrath and colleagues were the first to demonstrate increased excretion of $5 \mathrm{a}-$ reduced products and intermediates of the backdoor pathway in 142 patients with $\mathrm{CAH}$ between 1 and 25 years old, compared to 138 similarly aged controls ${ }^{28}$. Using gas chromatography/mass spectrometry (GC/MS), they found significantly increased urinary excretion of 5a-pregnane-3a,17a-diol-20-one (Pdiol), the critical intermediate and a specific marker of the backdoor pathway, in patients with 21OHD. Furthermore, they reported 7 -fold elevations of urinary androsterone, the dominant 5a-reduced $\mathrm{C}_{19}$ steroid derived from both classical and backdoor pathways, in children and young adults with $21 \mathrm{OHD}$. In contrast, they found only a 2 -fold elevation in etiocholanolone, the $5 \beta$-reduced 
$\mathrm{C}_{19}$ derived only from the classical pathways. Importantly, $5 \mathrm{a}-/ 5 \beta$-reduced cortisol metabolites ratios were not different in controls and 21OHD, excluding a general increase in $5 a$-reductase activity to explain their data ${ }^{28}$.

\section{E. Diagnosis}

Diagnosis of 21OHD relies on elevated 17OHP, one of the direct substrates of the deficient enzyme. The 17OHP levels are reflective of disease severity. Most patients with classic $21 \mathrm{OHD}$ have 17OHP levels consistently above $10,000 \mathrm{ng} / \mathrm{dL}$, while unaffected patients typically have baseline $17 \mathrm{OHP}$ values below $200 \mathrm{ng} / \mathrm{dL}^{29}$. In nonclassic $21 \mathrm{OHD}$, a random $17 \mathrm{OHP}$ is often equivocal, and post-cosyntropin values $>1,200 \mathrm{ng} / \mathrm{dL}$ are required to make the diagnosis. A few nonclassic 21OHD patients who are compound heterozygotes for classic and nonclassic alleles will have stimulated $17 \mathrm{OHP}$ values $>10,000 \mathrm{ng} / \mathrm{dL}$, but by definition, they lack clinically significant adrenal insufficiency, with stimulated cortisol values $>14 \mu \mathrm{g} / \mathrm{dL}$.

E.1. Newborn screening-Screening of newborns for CAH is performed in all 50 of the United States. Screening decreases the time to diagnosis and improves morbidity and mortality ${ }^{30-33}$, particularly by preventing salt wasting crises. Males with $\mathrm{CAH}$ are more likely to not be diagnosed early clinically, as they do not exhibit genital ambiguity at birth.

First-tier screening utilizes dried blood spots on standard screening cards and measures $17 \mathrm{OHP}$ by immunofluorometric assay (DELFIA $®)$. A very high random 17OHP $(>20,000$ $\mathrm{ng} / \mathrm{dL}$ ) is diagnostic of 21OHD. False-positive results, however, are common in premature and severely ill infants ${ }^{34,35}$. Thus, weight and gestational age adjusted cutoffs for 17OHP improve the positive predictive value of screening ${ }^{36-38}$. False negative rates of up to $22 \%$ have been reported in infant screening 39,40 , particularly when mothers had been exposed to glucocorticoids prenatally. Although false negative results are reportedly more common in girls ${ }^{40}$, it is possible that missed males remained unidentified, while the diagnosis was more likely to be pursued in girls, who are born with ambiguous genitalia.

Some of the limitations of immunoassay-based screening can be overcome by adjudicating positive tests with a second-tier assay using liquid chromatography/tandem mass spectrometry (LC-MS/MS) ${ }^{41-43}$. In addition to increased specificity, LC-MS/MS can also quantify multiple steroids with one measurement. Elevated $21 \mathrm{dF}$ by LC-MS/MS has been shown to increase the sensitivity of newborn screening ${ }^{42}$ and better discriminate heterozygote carriers ${ }^{44}$. LC-MS/MS assays, however, are not widely available, are often time-consuming, and are prohibitively expensive for screening purposes currently.

E.2. Diagnosis of 210HD beyond infancy-Patients evaluated for clinical evidence of inappropriate androgen excess initially undergo testing of 17OHP in an early morning serum sample ${ }^{29}$. The gold standard for diagnosing any form of CAH in patients with indeterminate values is a cosyntropin stimulation test, which maximizes the ratio between the steroids upstream and downstream the enzymatic blockage ${ }^{45}$. Figure 3 shows suggested cutoff baseline and stimulated 17OHP values in patients with 21OHD. Genetic testing of CYP21A2 detects 90 to $95 \%$ of mutant alleles ${ }^{46}$ and is useful when steroid results are equivocal ${ }^{47}$ or unreliable (hypopituitarism) and for genetic counseling, particularly in nonclassic 21OHD. 
Because other forms of CAH are not tested, the cost is high and management is rarely changed, genetic testing is not routinely recommended.

\section{F. Clinical Features}

Salt wasting-Approximately three-quarters of patients with classic 21OHD have aldosterone deficiency and thus are prone to volume depletion and hyperkalemia ${ }^{48}$. Where neonatal screening is not performed, undiagnosed male infants might present with failure to thrive and dehydration in the first 2 weeks of life, which can lead to death if not appropriately recognized and treated. All untreated classic 21OHD patients waste salt during illness, but spontaneous volume depletion in a well infant defines "salt-wasting" disease, a term that has little utility beyond childhood.

Ambiguous genitalia and prenatal virilization-Girls with classic 21OHD of all severities are born with varying degrees of genital ambiguity. Prenatal exposure to adrenal androgens activates the androgen receptors in genital skin, favors clitoral enlargement and labial fusion, and interferes with the urogenital sinus septation, which normally occurs at 7 weeks of gestation in girls. The degree of virilization is classified according to the 5-point Prader scale (Figure 4). If virilization is severe (Prader 4-5), assignment to male sex of rearing might inadvertently occur, and in rare cases, parents choose to raise the child as a boy knowing the diagnosis.

Boys with classic 21OHD typically have normal male genitalia (Prader 5). Subtle findings, such as hyperpigmentation of the scrotum and enlarged phallus, might be present at birth.

Postanatal virilization-In inadequately treated classic 210HD, the adrenal androgen excess promotes further clitoral growth in girls and phallus enlargement in boys. Children with nonclassic 21OHD may exhibit evidence of androgen excess at various ages, such as premature pubarche and oily skin, but not genital virilization. Poorly controlled adolescent girls might experience hirsutism, acne, and irregular menses, similarly with polycystic ovarian syndrome patients ${ }^{48}$.

Growth-Both male and female infants with classic 21OHD are longer than average at birth $^{49}$. Increased circulating levels of sex steroids promote accelerated linear growth and bone maturation early in life, which results in below average final height, due to premature epiphiseal closure. Additionally, glucocorticoid treatment, especially when excessive, suppresses growth. A meta-analysis of data from 35 centers concluded that the near-final height of patients with classic 21OHD was -1.38 SD below the population mean and -1 SD below the predicted mid-parental height ${ }^{50}$. A multitude of factors influence adult height, including severity of disease ${ }^{51}$, age at diagnosis ${ }^{49}$, treatment regimen ${ }^{52,53}$ and compliance. These known factors, however, failed to prove significant individually in pooled data, possibly because of heterogeneity and inconsistent reporting between studies. Both boys and girls can experience central precocious puberty when control is poor or erratic, thought to be due to adrenal-derived sex steroid "priming" and withdrawal, which further compromises adult height. 
Psychosexual development-Girls with classic 21OHD show more male-pattern play, activities, and career preferences ${ }^{54,55}$. Additionally, some studies have found that affected girls display more aggressive behaviors and lower maternal drive as compared with their unaffected siblings ${ }^{56,57}$. Exposure to higher than normal androgens prenatally and in childhood is thought to "imprint" the brain, leading to masculine behavior but rarely to male gender identity if treated from birth.

Some studies suggest that females with 21OHD, particularly those with more severe forms, undergo male-like cognitive development, with higher visuospatial and logic performance and lower verbal abilities ${ }^{58-60}$. Data regarding the overall intelligence coefficient (IQ) of patients with $21 \mathrm{OHD}$ have been conflicting. It has been suggested that salt-wasting $21 \mathrm{OHD}$ might result in lower IQs, possibly due to electrolyte imbalances in infancy ${ }^{61}$. Conversely, other authors found no overall IQ or cross-gender performance differences between 21OHD patients and unaffected controls ${ }^{62}$.

Female reproduction-Women with $210 H D$ have lower fertility rates, which correlate inversely with disease severity ${ }^{63,64}$. The live-birth rates in salt-wasting classic $210 H D$ have been reported to be only up to $10 \%, 33-50 \%$ in simple virilizing forms, and $63-90 \%$ in nonclassic $21 \mathrm{OHD}$, the latter rate being similar to that observed in the general population ${ }^{65-69}$. Hormonal, anatomical, and psychosocial factors have been suggested to contribute to impaired fertility ${ }^{64}$. Adrenal androgen overproduction can inhibit ovarian folliculogenesis and disturb the normal gonadotropin secretion pattern ${ }^{69,70}$. Elevated adrenal-derived progesterone in the follicular phase interferes with the normal menstrual cycle and impairs sperm penetration ${ }^{66,71,72}$. Women with 210 HD may also have excessive ovarian androgen production ${ }^{73,74}$ and secondary $\operatorname{PCOS}^{75}$.

Non-hormonal contributors to decreased fertility in 21OHD women include distorted genital anatomy, such as vaginal stenosis and reduced clitoral sensitivity, as well as decreased sexual motivation ${ }^{67,76}$ and lower maternal interest ${ }^{54}$. Nevertheless, in women with classic $21 \mathrm{OHD}$ who attempt pregnancy under skilled management, fecundity rates are normal ${ }^{77}$.

In contrast to the frequent development of adrenal rest tumors in the testes of men with 21OHD, ovarian adrenal rest tumors have only sporadically been reported in affected women ${ }^{78-81}$. This difference could be due to several factors, including more difficult distinction of ectopic adrenal tissue from theca cells in the heterogeneous ovary, the position of the ovaries in the pelvis, and possibly better control in most women, in whom undesirable clinical manifestations of androgen excess might provide motivation for compliance.

Male reproduction-Fertility in men with $21 \mathrm{OHD}$ has not been studied as extensively as in women. In the absence of newborn screening, boys with simple-virilizing 21OHD might remain undiagnosed, until they present with sexual precocity, accelerated growth, adrenal crisis during an infection, or rarely after fathering an affected girl. Studies from UK and Finland suggest that male fertility is well below that of the normal population ${ }^{82,83}$. The two main contributors to male infertility in 21OHD are hypogonadotropic hypogonadism, due to gonadal axis suppression from adrenal-derived androgens, and testicular adrenal rest tumors

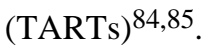


TARTs are typically bilateral masses, arising in the rete testes, thus often non-palpable when small $^{84}$. Ultrasound studies have identified TARTs in over $20 \%$ of boys ${ }^{86,87}$ and up to $94 \%$ of adults with classic $21 \mathrm{OHD}^{84,85,88}$. Some, but not all TARTs, regress following intensified glucocorticoid treatment ${ }^{89}$. The variable response might be in part due to fibrotic changes ${ }^{90}$ and to the number of adrenal-lineage cells, which migrated to the gonad during embryologic development ${ }^{91}$. TARTs may lead to obstruction of seminiferous tubules, gonadal dysfunction, and infertility ${ }^{84}$. Surgery to remove TARTs give good long-term control of tumor growth and mass effect ${ }^{92,93}$, but rarely restores fertility or testicular testosterone production ${ }^{93,94}$. For this reason, medical therapy is continued as primary treatment as long as the luteinizing hormone (LH) is in the normal range, the rests are shrinking, and the testosterone is rising, for at least 6 months and longer if tolerated. A rise in folliclestimulating hormone (FSH) and fall in inhibin B indicate loss of Sertoli cell function and poor prognosis for restoration of testicular function. Abrupt resumption of tight disease control in patients with TARTs and suppressed testicular function will lower serum testosterone into the hypogonadal range. To enhance compliance, the patient should be warned of these changes, and a gradual increase in medication should be considered. TARTs rarely if ever occur in men with nonclassic 21OHD. Little is known about fertility in men with nonclassic 21OHD, as few are ever diagnosed, and men with unexplained infertility are rarely tested for 21OHD.

Adrenal masses-A high prevalence of benign adrenal masses has been reported in patients with $21 \mathrm{OHD}$. Over $80 \%$ of homozygous and $45 \%$ of heterozygous patients had adrenal tumors in one study ${ }^{95}$, although no correlation between tumor size and serum $17 \mathrm{OHP}$ concentrations was found. Most tumors had a diameter of less than $2 \mathrm{~cm}$, but several giant myelolipomas have also been reported, typically in patients who are chronically undertreated $^{96-98}$.

Metabolic abnormalities-In a prospective cross-sectional study which followed 203 patients with CAH, $41 \%$ were obese, $46 \%$ had hypercholesterolemia, $29 \%$ were insulinresistant, $40 \%$ had osteopenia, and $7 \%$ had osteoporosis ${ }^{82}$. Similar findings have been reported in smaller studies ${ }^{99-101}$ and have been mostly attributed to glucocorticoid overtreatment.

\section{G. Management}

G.1. Medical treatment-Glucocorticoids and mineralocorticoids are the mainstays of treatment for 21OHD. Glucocorticoids exert two principal actions: replacement of the deficient cortisol and suppression of the adrenal androgen overproduction, by exerting negative feedback on the hypothalamus and the pituitary, which subsequently decreases $\mathrm{CRH}$ production and $\mathrm{ACTH}$ stimulation.

G.1.a. Glucocorticoid replacement: Patients with classic 21OHD all require chronic glucocorticoid replacement. Hydrocortisone is preferred in children and adolescents, until growth is completed, due to its short action, which limits the potential to suppress growth. A total of $10-17 \mathrm{mg} / \mathrm{m}^{2}$ daily divided in 2-3 doses is typically recommnended ${ }^{29}$, although it remains unclear if a specific dose distribution throughout the day has a significant clinical 
impact $^{102}$. The lowest possible dose should be used in order to avoid growth suppression $51,53,103,104$.

Hydrocortisone also serves as replacement therapy for adults, but long-acting synthetic glucocorticoids are often preferred, owing to less frequent dosing. The longer duration of action and higher potency of drugs like prednisolone and dexamethasone, however, might increase the risk of detrimental effects, including weight gain, dermal atrophy, poor sleep, and bone loss $82,105-108$.

Available treatment options and suggested doses are shown in Table 2. Stress doses of steroids should be given in patients with classic 210 HD during surgery, physical illness, labor and delivery ${ }^{29}$. In women attempting to conceive and during pregnancy, a glucocorticoid that is inactivated by placental $11 \beta$-hydroxysteroid dehydrogenase type 2 (e.g., hydrocortisone, prednisone, and prednisolone) should be used, to avoid fetal exposure.

Asymptomatic patients with nonclassic 210HD do not require treatment, and stress doses of steroids are rarely needed. Glucocorticoid treatment is primarily given to children with sexual precocity and advanced bone age or to women with infertility due to this condition. For other consequences of androgen excess, including acne, hirsutism, or body odor, alternatives therapies include anti-androgens (spironolactone), oral contraceptives, and mechanical depilation. When treated, replacement regimens are similar to those prescribed to classic $210 \mathrm{OHD}$ patients with lower doses. One retrospective series found high rates of pregnancy loss in women with nonclassic 21OHD, but this rate was lower in women who were treated with glucocorticoids ${ }^{109}$. For this reason, glucocorticoids (hydrocortisone) are often continued throughout gestation, particularly in women who conceive while taking glucocorticoids.

The goals of therapy for classic $210 \mathrm{HD}$ are to replace the hormonal deficits, while adequately suppressing the androgen excess. This balance is often hard to achieve without causing iatrogenic Cushing syndrome. Near-normalization of AD in both men and women and of testosterone in women indicates adequate control in most circumstances. Conversely, the $17 \mathrm{OHP}$ should not be consistently in the normal range; values of 1,000-3,000 ng/dL are acceptable if androgens production is controlled ${ }^{110}$. An exception is women attempting pregnancy, in whom treatment needs to be intensified to keep the follicular-phase progesterone suppressed $(<0.6 \mathrm{ng} / \mathrm{mL})$. Men with TARTs require at least one dose of a longacting glucocorticoid to keep the ACTH suppressed and to allow regression.

G.1. b. Mineralocorticoid replacement: Mineralocorticoid replacement (fludrocortisone acetate, $0.1-0.3 \mathrm{mg}$ daily) is necessary in patients with classic $210 \mathrm{HD}$. Infants with the most severe (salt-wasting) forms of disease need higher mineralocorticoid doses and additionally require supplementation with sodium chloride (1-2 g sodium chloride daily) while the renal function matures ${ }^{111}$. Mineralocorticoid replacement is generally maintained but occasionally becomes unnecessary in adults, possibly due to extra-adrenal 21-hydroxylation of adrenalderived progesterone ${ }^{112,113}$. Mineralocorticoid replacement and restoration of euvolemia decreases vasopressin and ACTH secretion, which often lowers the dose of glucocorticoid required to achieve adequate control of androgen production ${ }^{50,103}$. The dose of 
fludrocortisone is titrated to achieve normal sitting and standing blood pressure without an orthostatic drop, plasma renin activity near the lower limit of the normal range, and normal serum potassium; reevaluations should occur periodically.

G.1.c. Experimental therapy: Addition of the antiandrogen flutamide and the aromatase inhibitor testolactone allowed the use of lower doses of hydrocortisone and fludrocortisone acetate and normalized linear growth and bone maturation in children followed for 2 years ${ }^{114,115}$. Growth hormone, with or without a GnRH agonist, improved final height in some studies ${ }^{116,117}$. Additionally, GnRH antagonist has been successful in improving height in children with $21 \mathrm{OHD}$ and precocious puberty ${ }^{117}$. Abiraterone acetate, a potent CYP17A1 inhibitor indicated for testosterone suppression in patients with prostate cancer, when added to physiologic doses of hydrocortisone and fludrocortisone acetate, normalizes AD in adult women with classic $21 \mathrm{OHD}$ and elevated androgens ${ }^{118}$. Extended-release hydrocortisone preparations, which might improve compliance and limit the need for more potent glucocorticoids, are being studied ${ }^{119}$. Long-term safety data on all of these agents are lacking, and large, randomized controlled studies are yet needed.

\section{G.2. Surgical treatment}

G.2.a. Reconstructive surgery: For girls with virilized genitalia, surgery has been used to normalize voiding and to enable vaginal intercourse, but no good evidence to support a specific timing for surgical correction exists. A multidisciplinary team gathering expertise from pediatric endocrinologists, surgeons, social workers and psychologists should support the family into making an individualized decision. Advantages of early surgery include tissue malleability ${ }^{120}$ and decreased psychological impact on both affected girls and parents ${ }^{63,121}$. A potential benefit of delaying surgery until adolescence or young adulthood is incorporating patient autonomy in the decision-making process.

A two-step neurovascular-sparing clitoroplasty and vaginoplasty using total or partial urogenital mobilization is the preferred surgical approach, for minimizing clitoral insensitivity and urinary incontinence ${ }^{29,122}$. Good long-term outcomes data are difficult to obtain, due to the variations in surgical approach, baseline anatomy, hormonal control, and other mitigating factors. Post-surgical complications such as urethra-vaginal fistulae, impaired sensation, and vaginal stenosis, have been described, and current procedures strive to minimize these complications. The evolution of urogenital function following these procedures is particularly critical for young women contemplating pregnancy.

G.2.b. Elective adrenalectomy: Bilateral adrenalectomy has been performed in selected patients with severe forms of $21 \mathrm{OHD}$, in whom hyperandrogenism was difficult to control despite generous glucocorticoid replacement or in order to avoid their associated side effects $^{123-125}$. The ensuing primary adrenal insufficiency, however, is more tenuous than 21OHD and mandates strict adherence to lifelong glucocorticoid and mineralocorticoid replacement, in order to prevent potentially fatal adrenal crises ${ }^{125,126}$. Complete absence of epinephrine and DHEA are additional theoretical concerns, but the consequences of these deficiencies remain unknown. 
G.3. Prenatal diagnosis and treatment-The goal of prenatal treatment is to prevent virilization of external genitalia in female fetuses with classic 210HD. Administration of a glucocorticoid that is not degraded by the placenta, such as dexamethasone, suppresses fetal ACTH and the adrenal hyperandrogenism. Because virilization of affected females starts as soon as the sixth week of gestation ${ }^{127}$, treatment has to be initiated as soon as pregnancy is documented ${ }^{128-131}$. Treatment initiated after nine weeks of gestation will be incompletely effective ${ }^{132}$; therefore, early diagnosis is required if prenatal treatment is desired. Chorionic villus sampling and rapid genotypic of fetal cells is performed at 11 weeks of gestation ${ }^{133}$, and treatment is discontinued if genetic testing reveals a male or unaffected female fetus. Screening for the most common CYP21A2 mutations identifies approximately $90 \%$ of the affected patients ${ }^{46}$, but screening does not detect other forms of CAH. These procedures and treatments are costly and involve some risk to the mother. Earlier diagnosis appears to be possible by targeted massively parallel sequencing performed on cell-free fetal DNA circulating in maternal plasma at five weeks gestation ${ }^{134,135}$, and this approach might facilitate the decision of whom to treat.

Dexamethasone prevents or reduces virilization in over $85 \%$ of prenatally treated girls ${ }^{132}$. On the other hand, data regarding maternal and fetal long-term safety are scarce ${ }^{136}$. In the absence of a diagnosis when treatment must commence, seven unaffected children receive treatment to prevent virilization in one affected female on average. Parents should receive counseling regarding potential side effects and give informed consent to treatment. If elected, treatment from an experienced team in research centers that monitor outcomes is recommended 29 .

\section{Summary and future directions}

Adrenal biosynthesis of mineralocorticoids, glucocorticoids and androgen precursors follow specific enzymatic cascades in distinct, concentric adrenal zones, a design that optimizes steroid production efficiency. CAH results from autosomal recessive enzymatic defects in cortisol biosynthesis. The most common form is $21 \mathrm{OHD}$, accounting for over $90 \%$ of CAH cases. The clinical spectrum ranges from severe or classic forms, of which $75 \%$ have both mineralocorticoid and glucocorticoid deficiency, to mild, nonclassic 21OHD, in which ACTH overstimulation compensates for the partial block in cortisol production. All forms are characterized by excessive adrenal androgen production, which parallels the severity of the enzymatic defect. Diagnosis of 21OHD is based on elevations of 17OHP and is included in standard newborn screening throughout the US and many other countries. Although this approach is excellent in distinguishing the classic forms and unaffected individuals, it suffers from false positive and negative results and poorer discrimination of intermediate severity cases from heterozygote carriers. Incorporation of other steroids upstream the enzymatic defect such as $21 \mathrm{dF}$ in the diagnostic panel, as well as wider use of second-tier mass spectrometry assays, might increase sensitivity and specificity in future.

Glucocorticoids and, when needed, mineralocorticoids, are the mainstay of treatment in 21OHD. These serve both in replacing the deficient steroids, as well as in suppressing the excessive adrenal androgen production. New treatments under study include sustainedrelease hydrocortisone and inhibitors of androgen biosynthesis. Balancing and accurately 
monitoring treatment remains clinically challenging. 17OHP, $\mathrm{AD}$ and, in women, testosterone, have been utilized for treatment adjustment, but they do not always correlate well with clinical evidence of androgen excess. The identification and validation of adrenalspecific steroids and other molecules, which can be employed clinically as biomarkers of adrenal-derived androgen production, would be of major clinical utility to facilitate treatment monitoring.

\section{References}

*1. Miller WL, Auchus RJ. The molecular biology, biochemistry, and physiology of human steroidogenesis and its disorders. Endocrine reviews. Feb; 2011 32(1):81-151. [PubMed: 21051590]

2. Clark BJ, Wells J, King SR, Stocco DM. The purification, cloning, and expression of a novel luteinizing hormone-induced mitochondrial protein in MA-10 mouse Leydig tumor cells. Characterization of the steroidogenic acute regulatory protein (StAR). The Journal of biological chemistry. Nov 11; 1994 269(45):28314-28322. [PubMed: 7961770]

3. Koritz SB, Kumar AM. On the mechanism of action of the adrenocorticotrophic hormone. The stimulation of the activity of enzymes involved in pregnenolone synthesis. The Journal of biological chemistry. Jan 10; 1970 245(1):152-159. [PubMed: 4391541]

4. Lachance $\mathrm{Y}$, Luu-The V, Labrie C, et al. Characterization of human $3 \beta$-hydroxysteroid dehydrogenase/delta 5delta 4-isomerase gene and its expression in mammalian cells. The Journal of biological chemistry. Nov 25; 1990 265(33):20469-20475. [PubMed: 2243100]

5. White PC. Disorders of aldosterone biosynthesis and action. The New England journal of medicine. Jul 28; 1994 331(4):250-258. [PubMed: 8015573]

6. Wang XL, Bassett M, Zhang Y, et al. Transcriptional regulation of human 11 $\beta$-hydroxylase (hCYP11B1). Endocrinology. Oct; 2000 141(10):3587-3594. [PubMed: 11014212]

7. Auchus RJ, Lee TC, Miller WL. Cytochrome b5 augments the 17,20-lyase activity of human P450c17 without direct electron transfer. The Journal of biological chemistry. Feb 6; 1998 273(6): 3158-3165. [PubMed: 9452426]

8. Noordam C, Dhir V, McNelis JC, et al. Inactivating PAPSS2 mutations in a patient with premature pubarche. The New England journal of medicine. May 28; 2009 360(22):2310-2318. [PubMed: 19474428]

9. Reiter EO, Fuldauer VG, Root AW. Secretion of the adrenal androgen, dehydroepiandrosterone sulfate, during normal infancy, childhood, and adolescence, in sick infants, and in children with endocrinologic abnormalities. The Journal of pediatrics. May; 1977 90(5):766-770. [PubMed: 140222]

10. Rosenfield RL, Grossman BJ, Ozoa N. Plasma 17-ketosteroids and testosterone in prepubertal children before and after ACTH administration. The Journal of clinical endocrinology and metabolism. Aug; 1971 33(2):249-253. [PubMed: 4327687]

11. Speiser PW, White PC. Congenital adrenal hyperplasia. The New England journal of medicine. Aug 21; 2003 349(8):776-788. [PubMed: 12930931]

12. Auchus, R. Genetic deficiencies of cytochrome P450c17 (CYP17A1): combined 17-hydroxylase/ 17,20-lyase and isolated 17,20-lyase deficiency. In: New, M., editor. Genetic Steroid Disorders. Elsevier; Waltham, MA: 2014. p. 111-123.

13. Krone N, Riepe FG, Gotze D, et al. Congenital adrenal hyperplasia due to 11-hydroxylase deficiency: functional characterization of two novel point mutations and a three-base pair deletion in the CYP11B1 gene. The Journal of clinical endocrinology and metabolism. Jun; 2005 90(6): 3724-3730. [PubMed: 15755848]

14. Pang S. Congenital adrenal hyperplasia owing to $3 \beta$-hydroxysteroid dehydrogenase deficiency. Endocrinology and metabolism clinics of North America. Mar; 2001 30(1):81-99. vi-vii. [PubMed: 11344940] 
15. Bose HS, Sugawara T, Strauss JF 3rd, Miller WL, International Congenital Lipoid Adrenal Hyperplasia C. The pathophysiology and genetics of congenital lipoid adrenal hyperplasia. The New England journal of medicine. Dec 19; 1996 335(25):1870-1878. [PubMed: 8948562]

16. Parajes S, Chan AO, But WM, et al. Delayed diagnosis of adrenal insufficiency in a patient with severe penoscrotal hypospadias due to two novel P450 side-change cleavage enzyme (CYP11A1) mutations (p.R360W; p.R405X). European journal of endocrinology / European Federation of Endocrine Societies. Dec; 2012 167(6):881-885. [PubMed: 22968487]

17. Krone N, Dhir V, Ivison HE, Arlt W. Congenital adrenal hyperplasia and P450 oxidoreductase deficiency. Clinical endocrinology. Feb; 2007 66(2):162-172. [PubMed: 17223983]

18. Therrell BL. Newborn screening for congenital adrenal hyperplasia. Endocrinology and metabolism clinics of North America. Mar; 2001 30(1):15-30. [PubMed: 11344933]

19. Speiser PW, Dupont B, Rubinstein P, Piazza A, Kastelan A, New MI. High frequency of nonclassical steroid 21-hydroxylase deficiency. American journal of human genetics. Jul; 1985 37(4):650-667. [PubMed: 9556656]

20. Carroll MC, Campbell RD, Porter RR. Mapping of steroid 21-hydroxylase genes adjacent to complement component C4 genes in HLA, the major histocompatibility complex in man. Proceedings of the National Academy of Sciences of the United States of America. Jan; 1985 82(2):521-525. [PubMed: 3871526]

21. White PC, Grossberger D, Onufer BJ, et al. Two genes encoding steroid 21-hydroxylase are located near the genes encoding the fourth component of complement in man. Proceedings of the National Academy of Sciences of the United States of America. Feb; 1985 82(4):1089-1093. [PubMed: 2983330]

22. White PC, New MI, Dupont B. Structure of human steroid 21-hydroxylase genes. Proceedings of the National Academy of Sciences of the United States of America. Jul; 1986 83(14):5111-5115. [PubMed: 3487786]

23. White PC, Speiser PW. Congenital adrenal hyperplasia due to 21-hydroxylase deficiency. Endocrine reviews. Jun; 2000 21(3):245-291. [PubMed: 10857554]

24. Swart AC, Storbeck KH, Swart P. A single amino acid residue, Ala 105, confers 16a-hydroxylase activity to human cytochrome P450 17a-hydroxylase/17,20 lyase. The Journal of steroid biochemistry and molecular biology. Apr; 2010 119(3-5):112-120. [PubMed: 20043997]

25. Fluck CE, Miller WL, Auchus RJ. The 17, 20-lyase activity of cytochrome p450c17 from human fetal testis favors the delta5 steroidogenic pathway. The Journal of clinical endocrinology and metabolism. Aug; 2003 88(8):3762-3766. [PubMed: 12915666]

26. Wilson JD, Auchus RJ, Leihy MW, et al. 5a-androstane-3a,17 $\beta$-diol is formed in tammar wallaby pouch young testes by a pathway involving 5a-pregnane-3a,17a-diol-20-one as a key intermediate. Endocrinology. Feb; 2003 144(2):575-580. [PubMed: 12538619]

27. Auchus RJ. The backdoor pathway to dihydrotestosterone. Trends in endocrinology and metabolism: TEM. Nov; 2004 15(9):432-438. [PubMed: 15519890]

28. Kamrath C, Hochberg Z, Hartmann MF, Remer T, Wudy SA. Increased activation of the alternative "backdoor" pathway in patients with 21-hydroxylase deficiency: evidence from urinary steroid hormone analysis. The Journal of clinical endocrinology and metabolism. Mar; 2012 97(3):E367-375. [PubMed: 22170725]

29. Speiser PW, Azziz R, Baskin LS, et al. Congenital adrenal hyperplasia due to steroid 21hydroxylase deficiency: an Endocrine Society clinical practice guideline. The Journal of clinical endocrinology and metabolism. Sep; 2010 95(9):4133-4160. [PubMed: 20823466]

30. Balsamo A, Cacciari E, Piazzi S, et al. Congenital adrenal hyperplasia: neonatal mass screening compared with clinical diagnosis only in the Emilia-Romagna region of Italy, 1980-1995. Pediatrics. Sep; 1996 98(3):362-367. Pt 1. [PubMed: 8784357]

31. Brosnan PG, Brosnan CA, Kemp SF, et al. Effect of newborn screening for congenital adrenal hyperplasia. Archives of pediatrics \& adolescent medicine. Dec; 1999 153(12):1272-1278. [PubMed: 10591305]

32. Therrell BL Jr. Berenbaum SA, Manter-Kapanke V, et al. Results of screening 1.9 million Texas newborns for 21-hydroxylase-deficient congenital adrenal hyperplasia. Pediatrics. Apr; 1998 101(4):583-590. Pt 1. [PubMed: 9521938] 
33. Thil'en A, Nordenstrom A, Hagenfeldt L, von Dobeln U, Guthenberg C, Larsson A. Benefits of neonatal screening for congenital adrenal hyperplasia (21-hydroxylase deficiency) in Sweden. Pediatrics. Apr.1998 101(4):E11. [PubMed: 9521977]

34. Cavarzere P, Samara-Boustani D, Flechtner I, et al. Transient hyper-17-hydroxyprogesteronemia: a clinical subgroup of patients diagnosed at neonatal screening for congenital adrenal hyperplasia. European journal of endocrinology / European Federation of Endocrine Societies. Aug; 2009 161(2):285-292. [PubMed: 19451212]

35. Coulm B, Coste J, Tardy V, et al. Efficiency of neonatal screening for congenital adrenal hyperplasia due to 21-hydroxylase deficiency in children born in mainland France between 1996 and 2003. Archives of pediatrics \& adolescent medicine. Feb; 2012 166(2):113-120. [PubMed: 22312171]

36. Steigert M, Schoenle EJ, Biason-Lauber A, Torresani T. High reliability of neonatal screening for congenital adrenal hyperplasia in Switzerland. The Journal of clinical endocrinology and metabolism. Sep; 2002 87(9):4106-4110. [PubMed: 12213856]

37. Olgemoller B, Roscher AA, Liebl B, Fingerhut R. Screening for congenital adrenal hyperplasia: adjustment of 17-hydroxyprogesterone cut-off values to both age and birth weight markedly improves the predictive value. The Journal of clinical endocrinology and metabolism. Dec; 2003 88(12):5790-5794. [PubMed: 14671170]

38. van der Kamp HJ, Oudshoorn CG, Elvers BH, et al. Cutoff levels of 17a-hydroxyprogesterone in neonatal screening for congenital adrenal hyperplasia should be based on gestational age rather than on birth weight. The Journal of clinical endocrinology and metabolism. Jul; 2005 90(7):39043907. [PubMed: 15797960]

39. Sarafoglou K, Banks K, Kyllo J, Pittock S, Thomas W. Cases of congenital adrenal hyperplasia missed by newborn screening in Minnesota. Jama. Jun 13; 2012 307(22):2371-2374. [PubMed: 22692165]

40. Varness TS, Allen DB, Hoffman GL. Newborn screening for congenital adrenal hyperplasia has reduced sensitivity in girls. The Journal of pediatrics. Oct; 2005 147(4):493-498. [PubMed: 16227036]

41. Schwarz E, Liu A, Randall H, et al. Use of steroid profiling by UPLC-MS/MS as a second tier test in newborn screening for congenital adrenal hyperplasia: the Utah experience. Pediatric research. Aug; 2009 66(2):230-235. [PubMed: 19390483]

42. Janzen N, Peter M, Sander S, et al. Newborn screening for congenital adrenal hyperplasia: additional steroid profile using liquid chromatography-tandem mass spectrometry. The Journal of clinical endocrinology and metabolism. Jul; 2007 92(7):2581-2589. [PubMed: 17456574]

43. Janzen N, Sander S, Terhardt M, Peter M, Sander J. Fast and direct quantification of adrenal steroids by tandem mass spectrometry in serum and dried blood spots. Journal of chromatography. B, Analytical technologies in the biomedical and life sciences. Jan 1; 2008 861(1):117-122. [PubMed: 18053779]

44. Costa-Barbosa FA, Tonetto-Fernandes VF, Carvalho VM, et al. Superior discriminating value of ACTH-stimulated serum 21-deoxycortisol in identifying heterozygote carriers for 21-hydroxylase deficiency. Clinical endocrinology. Dec; 2010 73(6):700-706. [PubMed: 20846292]

45. New MI, Lorenzen F, Lerner AJ, et al. Genotyping steroid 21-hydroxylase deficiency: hormonal reference data. The Journal of clinical endocrinology and metabolism. Aug; 1983 57(2):320-326. [PubMed: 6306039]

46. Finkielstain GP, Chen W, Mehta SP, et al. Comprehensive genetic analysis of 182 unrelated families with congenital adrenal hyperplasia due to 21-hydroxylase deficiency. The Journal of clinical endocrinology and metabolism. Jan; 2011 96(1):E161-172. [PubMed: 20926536]

47. Nordenstrom A, Thilen A, Hagenfeldt L, Larsson A, Wedell A. Genotyping is a valuable diagnostic complement to neonatal screening for congenital adrenal hyperplasia due to steroid 21hydroxylase deficiency. The Journal of clinical endocrinology and metabolism. May; 1999 84(5): 1505-1509. [PubMed: 10323369]

48. White PC, Bachega TA. Congenital adrenal hyperplasia due to 21 hydroxylase deficiency: from birth to adulthood. Seminars in reproductive medicine. Oct; 2012 30(5):400-409. [PubMed: 23044877] 
49. Jaaskelainen J, Voutilainen R. Growth of patients with 21-hydroxylase deficiency: an analysis of the factors influencing adult height. Pediatric research. Jan; 1997 41(1):30-33. [PubMed: 8979286]

50. Muthusamy K, Elamin MB, Smushkin G, et al. Clinical review: Adult height in patients with congenital adrenal hyperplasia: a systematic review and metaanalysis. The Journal of clinical endocrinology and metabolism. Sep; 2010 95(9):4161-4172. [PubMed: 20823467]

51. Manoli I, Kanaka-Gantenbein C, Voutetakis A, Maniati-Christidi M, Dacou-Voutetakis C. Early growth, pubertal development, body mass index and final height of patients with congenital adrenal hyperplasia: factors influencing the outcome. Clinical endocrinology. Nov; 2002 57(5): 669-676. [PubMed: 12390343]

52. Kirkland RT, Keenan BS, Holcombe JH, Kirkland JL, Clayton GW. The effect of therapy on mature height in congenital adrenal hyperplasia. The Journal of clinical endocrinology and metabolism. Dec; 1978 47(6):1320-1324. [PubMed: 263352]

53. Grigorescu-Sido A, Bettendorf M, Schulze E, Duncea I, Heinrich U. Growth analysis in patients with 21-hydroxylase deficiency influence of glucocorticoid dosage, age at diagnosis, phenotype and genotype on growth and height outcome. Hormone research. 2003; 60(2):84-90. [PubMed: 12876419]

54. Dittmann RW, Kappes MH, Kappes ME, et al. Congenital adrenal hyperplasia. I: Gender-related behavior and attitudes in female patients and sisters. Psychoneuroendocrinology. 1990; 15(5-6): 401-420. [PubMed: 2101963]

55. Berenbaum SA. Effects of early androgens on sex-typed activities and interests in adolescents with congenital adrenal hyperplasia. Hormones and behavior. Feb; 1999 35(1):102-110. [PubMed: 10049608]

56. Berenbaum SA, Resnick SM. Early androgen effects on aggression in children and adults with congenital adrenal hyperplasia. Psychoneuroendocrinology. Oct; 1997 22(7):505-515. [PubMed: 9373884]

57. Mathews GA, Fane BA, Conway GS, Brook CG, Hines M. Personality and congenital adrenal hyperplasia: possible effects of prenatal androgen exposure. Hormones and behavior. Feb; 2009 55(2):285-291. [PubMed: 19100266]

58. Helleday J, Bartfai A, Ritzen EM, Forsman M. General intelligence and cognitive profile in women with congenital adrenal hyperplasia (CAH). Psychoneuroendocrinology. 1994; 19(4):343356. [PubMed: 8047639]

59. Kelso WM, Nicholls ME, Warne GL, Zacharin M. Cerebral lateralization and cognitive functioning in patients with congenital adrenal hyperplasia. Neuropsychology. Jul; 2000 14(3): 370-378. [PubMed: 10928740]

60. Mueller SC, Temple V, Oh E, et al. Early androgen exposure modulates spatial cognition in congenital adrenal hyperplasia (CAH). Psychoneuroendocrinology. Aug; 2008 33(7):973-980. [PubMed: 18675711]

61. Johannsen TH, Ripa CP, Reinisch JM, Schwartz M, Mortensen EL, Main KM. Impaired cognitive function in women with congenital adrenal hyperplasia. The Journal of clinical endocrinology and metabolism. Apr; 2006 91(4):1376-1381. [PubMed: 16449336]

62. Malouf MA, Migeon CJ, Carson KA, Petrucci L, Wisniewski AB. Cognitive outcome in adult women affected by congenital adrenal hyperplasia due to 21-hydroxylase deficiency. Hormone research. 2006; 65(3):142-150. [PubMed: 16508325]

63. Nordenskjold A, Holmdahl G, Frisen L, et al. Type of mutation and surgical procedure affect longterm quality of life for women with congenital adrenal hyperplasia. The Journal of clinical endocrinology and metabolism. Feb; 2008 93(2):380-386. [PubMed: 18029470]

64. Stikkelbroeck NM, Hermus AR, Braat DD, Otten BJ. Fertility in women with congenital adrenal hyperplasia due to 21-hydroxylase deficiency. Obstetrical \& gynecological survey. Apr; 2003 58(4):275-284. [PubMed: 12665708]

65. Jaaskelainen J, Hippelainen M, Kiekara O, Voutilainen R. Child rate, pregnancy outcome and ovarian function in females with classical 21-hydroxylase deficiency. Acta obstetricia et gynecologica Scandinavica. Aug; 2000 79(8):687-692. [PubMed: 10949235] 
66. Helleday J, Siwers B, Ritzen EM, Carlstrom K. Subnormal androgen and elevated progesterone levels in women treated for congenital virilizing 21-hydroxylase deficiency. The Journal of clinical endocrinology and metabolism. Apr; 1993 76(4):933-936. [PubMed: 8473408]

67. Mulaikal RM, Migeon CJ, Rock JA. Fertility rates in female patients with congenital adrenal hyperplasia due to 21-hydroxylase deficiency. The New England journal of medicine. Jan 22; 1987 316(4):178-182. [PubMed: 3491959]

68. Klingensmith GJ, Garcia SC, Jones HW, Migeon CJ, Blizzard RM. Glucocorticoid treatment of girls with congenital adrenal hyperplasia: effects on height, sexual maturation, and fertility. The Journal of pediatrics. Jun; 1977 90(6):996-1004. [PubMed: 870661]

69. Feldman S, Billaud L, Thalabard JC, et al. Fertility in women with late-onset adrenal hyperplasia due to 21-hydroxylase deficiency. The Journal of clinical endocrinology and metabolism. Mar; 1992 74(3):635-639. [PubMed: 1310999]

70. Hughes IA, Read GF. Menarche and subsequent ovarian function in girls with congenital adrenal hyperplasia. Hormone research. 1982; 16(2):100-106. [PubMed: 7106698]

71. Holmes-Walker DJ, Conway GS, Honour JW, Rumsby G, Jacobs HS. Menstrual disturbance and hypersecretion of progesterone in women with congenital adrenal hyperplasia due to 21hydroxylase deficiency. Clinical endocrinology. Sep; 1995 43(3):291-296. [PubMed: 7586597]

72. Rosenfield RL, Bickel S, Razdan AK. Amenorrhea related to progestin excess in congenital adrenal hyperplasia. Obstetrics and gynecology. Aug; 1980 56(2):208-215. [PubMed: 7393510]

73. Barnes RB, Rosenfield RL, Ehrmann DA, et al. Ovarian hyperandrogynism as a result of congenital adrenal virilizing disorders: evidence for perinatal masculinization of neuroendocrine function in women. The Journal of clinical endocrinology and metabolism. Nov; 1994 79(5):13281333. [PubMed: 7962325]

74. Ghizzoni L, Virdis R, Vottero A, et al. Pituitary-ovarian responses to leuprolide acetate testing in patients with congenital adrenal hyperplasia due to 21-hydroxylase deficiency. The Journal of clinical endocrinology and metabolism. Feb; 1996 81(2):601-606. [PubMed: 8636275]

75. Hague WM, Adams J, Rodda C, et al. The prevalence of polycystic ovaries in patients with congenital adrenal hyperplasia and their close relatives. Clinical endocrinology. Oct; 1990 33(4): 501-510. [PubMed: 2225492]

76. Kuhnle U, Bullinger M, Schwarz HP. The quality of life in adult female patients with congenital adrenal hyperplasia: a comprehensive study of the impact of genital malformations and chronic disease on female patients life. European journal of pediatrics. Sep; 1995 154(9):708-716. [PubMed: 8582420]

77. Casteras A, De Silva P, Rumsby G, Conway GS. Reassessing fecundity in women with classical congenital adrenal hyperplasia $(\mathrm{CAH})$ : normal pregnancy rate but reduced fertility rate. Clinical endocrinology. Jun; 2009 70(6):833-837. [PubMed: 19250265]

78. Al-Ahmadie HA, Stanek J, Liu J, Mangu PN, Niemann T, Young RH. Ovarian 'tumor' of the adrenogenital syndrome: the first reported case. The American journal of surgical pathology. Nov; 2001 25(11):1443-1450. [PubMed: 11684964]

79. Russo G, Paesano P, Taccagni G, Del Maschio A, Chiumello G. Ovarian adrenal-like tissue in congenital adrenal hyperplasia. The New England journal of medicine. Sep 17; 1998 339(12):853854. [PubMed: 9750088]

80. Zaarour MG, Atallah DM, Trak-Smayra VE, Halaby GH. Bilateral ovary adrenal rest tumor in a congenital adrenal hyperplasia following adrenalectomy. Endocrine practice : official journal of the American College of Endocrinology and the American Association of Clinical Endocrinologists. Apr 1; 2014 20(4):e69-74.

81. Tiosano D, Vlodavsky E, Filmar S, Weiner Z, Goldsher D, Bar-Shalom R. Ovarian adrenal rest tumor in a congenital adrenal hyperplasia patient with adrenocorticotropin hypersecretion following adrenalectomy. Hormone research in paediatrics. 2010; 74(3):223-228. [PubMed: 20431278]

82. Arlt W, Willis DS, Wild SH, et al. Health status of adults with congenital adrenal hyperplasia: a cohort study of 203 patients. The Journal of clinical endocrinology and metabolism. Nov; 2010 95(11):5110-5121. [PubMed: 20719839] 
83. Jaaskelainen J, Kiekara O, Hippelainen M, Voutilainen R. Pituitary gonadal axis and child rate in males with classical 21-hydroxylase deficiency. Journal of endocrinological investigation. Jan; 2000 23(1):23-27. [PubMed: 10698047]

84. Stikkelbroeck NM, Otten BJ, Pasic A, et al. High prevalence of testicular adrenal rest tumors, impaired spermatogenesis, and Leydig cell failure in adolescent and adult males with congenital adrenal hyperplasia. The Journal of clinical endocrinology and metabolism. Dec; 2001 86(12): 5721-5728. [PubMed: 11739428]

85. Stikkelbroeck NM, Suliman HM, Otten BJ, Hermus AR, Blickman JG, Jager GJ. Testicular adrenal rest tumours in postpubertal males with congenital adrenal hyperplasia: sonographic and MR features. European radiology. Jul; 2003 13(7):1597-1603. [PubMed: 12835972]

86. Martinez-Aguayo A, Rocha A, Rojas N, et al. Testicular adrenal rest tumors and Leydig and Sertoli cell function in boys with classical congenital adrenal hyperplasia. The Journal of clinical endocrinology and metabolism. Dec; 2007 92(12):4583-4589. [PubMed: 17895312]

87. Claahsen-van der Grinten HL, Sweep FC, Blickman JG, Hermus AR, Otten BJ. Prevalence of testicular adrenal rest tumours in male children with congenital adrenal hyperplasia due to 21 hydroxylase deficiency. European journal of endocrinology / European Federation of Endocrine Societies. Sep; 2007 157(3):339-344. [PubMed: 17766717]

88. Falhammar H, Nystrom HF, Ekstrom U, Granberg S, Wedell A, Thoren M. Fertility, sexuality and testicular adrenal rest tumors in adult males with congenital adrenal hyperplasia. European journal of endocrinology / European Federation of Endocrine Societies. Mar; 2012 166(3):441-449. [PubMed: 22157069]

89. Rutgers JL, Young RH, Scully RE. The testicular "tumor" of the adrenogenital syndrome. A report of six cases and review of the literature on testicular masses in patients with adrenocortical disorders. The American journal of surgical pathology. Jul; 1988 12(7):503-513. [PubMed: 3291624]

90. Claahsen-van der Grinten HL, Otten BJ, Stikkelbroeck MM, Sweep FC, Hermus AR. Testicular adrenal rest tumours in congenital adrenal hyperplasia. Best practice \& research. Clinical endocrinology \& metabolism. Apr; 2009 23(2):209-220. [PubMed: 19500764]

91. Reisch N, Rottenkolber M, Greifenstein A, et al. Testicular adrenal rest tumors develop independently of long-term disease control: a longitudinal analysis of 50 adult men with congenital adrenal hyperplasia due to classic 21-hydroxylase deficiency. The Journal of clinical endocrinology and metabolism. Nov; 2013 98(11):E1820-1826. [PubMed: 23969190]

92. Ashley RA, McGee SM, Isotaolo PA, Kramer SA, Cheville JC. Clinical and pathological features associated with the testicular tumor of the adrenogenital syndrome. The Journal of urology. Feb; 2007 177(2):546-549. discussion 549. [PubMed: 17222630]

93. Walker BR, Skoog SJ, Winslow BH, Canning DA, Tank ES. Testis sparing surgery for steroid unresponsive testicular tumors of the adrenogenital syndrome. The Journal of urology. Apr; 1997 157(4):1460-1463. [PubMed: 9120982]

94. Claahsen-van der Grinten HL, Otten BJ, Takahashi S, et al. Testicular adrenal rest tumors in adult males with congenital adrenal hyperplasia: evaluation of pituitary-gonadal function before and after successful testis-sparing surgery in eight patients. The Journal of clinical endocrinology and metabolism. Feb; 2007 92(2):612-615. [PubMed: 17090637]

95. Jaresch S, Kornely E, Kley HK, Schlaghecke R. Adrenal incidentaloma and patients with homozygous or heterozygous congenital adrenal hyperplasia. The Journal of clinical endocrinology and metabolism. Mar; 1992 74(3):685-689. [PubMed: 1311000]

96. Nermoen I, Rorvik J, Holmedal SH, et al. High frequency of adrenal myelolipomas and testicular adrenal rest tumours in adult Norwegian patients with classical congenital adrenal hyperplasia because of 21-hydroxylase deficiency. Clinical endocrinology. Dec; 2011 75(6):753-759. [PubMed: 21689130]

97. German-Mena E, Zibari GB, Levine SN. Adrenal myelolipomas in patients with congenital adrenal hyperplasia: review of the literature and a case report. Endocrine practice : official journal of the American College of Endocrinology and the American Association of Clinical Endocrinologists. May-Jun;2011 17(3):441-447. 
98. McGeoch SC, Olson S, Krukowski ZH, Bevan JS. Giant bilateral myelolipomas in a man with congenital adrenal hyperplasia. The Journal of clinical endocrinology and metabolism. Feb; 2012 97(2):343-344. [PubMed: 22238394]

99. Reisch N, Arlt W, Krone N. Health problems in congenital adrenal hyperplasia due to 21hydroxylase deficiency. Hormone research in paediatrics. 2011; 76(2):73-85. [PubMed: 21597280]

100. Falhammar H, Filipsson H, Holmdahl G, et al. Metabolic profile and body composition in adult women with congenital adrenal hyperplasia due to 21-hydroxylase deficiency. The Journal of clinical endocrinology and metabolism. Jan; 2007 92(1):110-116. [PubMed: 17032717]

101. Mooij CF, Kroese JM, Claahsen-van der Grinten HL, Tack CJ, Hermus AR. Unfavourable trends in cardiovascular and metabolic risk in paediatric and adult patients with congenital adrenal hyperplasia? Clinical endocrinology. Aug; 2010 73(2):137-146. [PubMed: 19719762]

102. German A, Suraiya S, Tenenbaum-Rakover Y, Koren I, Pillar G, Hochberg Z. Control of childhood congenital adrenal hyperplasia and sleep activity and quality with morning or evening glucocorticoid therapy. The Journal of clinical endocrinology and metabolism. Dec; 2008 93(12): 4707-4710. [PubMed: 18782876]

103. Balsamo A, Cicognani A, Baldazzi L, et al. CYP21 genotype, adult height, and pubertal development in 55 patients treated for 21-hydroxylase deficiency. The Journal of clinical endocrinology and metabolism. Dec; 2003 88(12):5680-5688. [PubMed: 14671153]

104. Bonfig W, Pozza SB, Schmidt H, Pagel P, Knorr D, Schwarz HP. Hydrocortisone dosing during puberty in patients with classical congenital adrenal hyperplasia: an evidence-based recommendation. The Journal of clinical endocrinology and metabolism. Oct; 2009 94(10):38823888. [PubMed: 19622620]

105. Horrocks PM, London DR. Effects of long term dexamethasone treatment in adult patients with congenital adrenal hyperplasia. Clinical endocrinology. Dec; 1987 27(6):635-642. [PubMed: 2843311]

106. Young MC, Hughes IA. Dexamethasone treatment for congenital adrenal hyperplasia. Archives of disease in childhood. Mar; 1990 65(3):312-314. [PubMed: 2334212]

107. El-Maouche D, Collier S, Prasad M, Reynolds JC, Merke DP. Cortical bone mineral density in patients with congenital adrenal hyperplasia due to 21-hydroxylase deficiency. Clinical endocrinology. May 24.2014

108. Falhammar H, Filipsson Nystrom H, Wedell A, Brismar K, Thoren M. Bone mineral density, bone markers, and fractures in adult males with congenital adrenal hyperplasia. European journal of endocrinology / European Federation of Endocrine Societies. Mar; 2013 168(3):331-341. [PubMed: 23211577]

109. Bidet M, Bellanne-Chantelot C, Galand-Portier MB, et al. Fertility in women with nonclassical congenital adrenal hyperplasia due to 21-hydroxylase deficiency. The Journal of clinical endocrinology and metabolism. Mar; 2010 95(3):1182-1190. [PubMed: 20080854]

110. Auchus RJ. Congenital adrenal hyperplasia in adults. Current opinion in endocrinology, diabetes, and obesity. Jun; 2010 17(3):210-216.

111. Mullis PE, Hindmarsh PC, Brook CG. Sodium chloride supplement at diagnosis and during infancy in children with salt-losing 21-hydroxylase deficiency. European journal of pediatrics. Nov; 1990 150(1):22-25. [PubMed: 2079072]

112. Gomes LG, Huang N, Agrawal V, Mendonca BB, Bachega TA, Miller WL. Extraadrenal 21hydroxylation by CYP2C19 and CYP3A4: effect on 21-hydroxylase deficiency. The Journal of clinical endocrinology and metabolism. Jan; 2009 94(1):89-95. [PubMed: 18957504]

113. Speiser PW, Agdere L, Ueshiba H, White PC, New MI. Aldosterone synthesis in salt-wasting congenital adrenal hyperplasia with complete absence of adrenal 21-hydroxylase. The New England journal of medicine. Jan 17; 1991 324(3):145-149. [PubMed: 1984191]

114. Laue L, Merke DP, Jones JV, Barnes KM, Hill S, Cutler GB Jr. A preliminary study of flutamide, testolactone, and reduced hydrocortisone dose in the treatment of congenital adrenal hyperplasia. The Journal of clinical endocrinology and metabolism. Oct; 1996 81(10):3535-3539. [PubMed: 8855797] 
115. Merke DP, Keil MF, Jones JV, Fields J, Hill S, Cutler GB Jr. Flutamide, testolactone, and reduced hydrocortisone dose maintain normal growth velocity and bone maturation despite elevated androgen levels in children with congenital adrenal hyperplasia. The Journal of clinical endocrinology and metabolism. Mar; 2000 85(3):1114-1120. [PubMed: 10720048]

116. Quintos JB, Vogiatzi MG, Harbison MD, New MI. Growth hormone therapy alone or in combination with gonadotropin-releasing hormone analog therapy to improve the height deficit in children with congenital adrenal hyperplasia. The Journal of clinical endocrinology and metabolism. Apr; 2001 86(4):1511-1517. [PubMed: 11297576]

117. Lin-Su K, Vogiatzi MG, Marshall I, et al. Treatment with growth hormone and luteinizing hormone releasing hormone analog improves final adult height in children with congenital adrenal hyperplasia. The Journal of clinical endocrinology and metabolism. Jun; 2005 90(6): 3318-3325. [PubMed: 15797962]

118. Auchus RJ, Buschur EO, Chang AY, et al. Abiraterone acetate to lower androgens in women with classic 21-hydroxylase deficiency. The Journal of clinical endocrinology and metabolism. Aug; 2014 99(8):2763-2770. [PubMed: 24780050]

119. Verma S, Vanryzin C, Sinaii N, et al. A pharmacokinetic and pharmacodynamic study of delayedand extended-release hydrocortisone (Chronocort) vs. conventional hydrocortisone (Cortef) in the treatment of congenital adrenal hyperplasia. Clinical endocrinology. Apr; 2010 72(4):441447. [PubMed: 19486026]

120. Bernbaum JC, Umbach DM, Ragan NB, et al. Pilot studies of estrogen-related physical findings in infants. Environmental health perspectives. Mar; 2008 116(3):416-420. [PubMed: 18335112]

121. Wisniewski AB, Migeon CJ, Malouf MA, Gearhart JP. Psychosexual outcome in women affected by congenital adrenal hyperplasia due to 21-hydroxylase deficiency. The Journal of urology. Jun; 2004 171(6):2497-2501. Pt 1. [PubMed: 15126884]

122. Pena A. Total urogenital mobilization--an easier way to repair cloacas. Journal of pediatric surgery. Feb; 1997 32(2):263-267. discussion 267-268. [PubMed: 9044134]

123. Gunther DF, Bukowski TP, Ritzen EM, Wedell A, Van Wyk JJ. Prophylactic adrenalectomy of a three-year-old girl with congenital adrenal hyperplasia: pre- and postoperative studies. The Journal of clinical endocrinology and metabolism. Oct; 1997 82(10):3324-3327. [PubMed: 9329362]

124. Bruining H, Bootsma AH, Koper JW, Bonjer J, de Jong FF, Lamberts SW. Fertility and body composition after laparoscopic bilateral adrenalectomy in a 30-year-old female with congenital adrenal hyperplasia. The Journal of clinical endocrinology and metabolism. Feb; 2001 86(2): 482-484. [PubMed: 11157995]

125. Van Wyk JJ, Ritzen EM. The role of bilateral adrenalectomy in the treatment of congenital adrenal hyperplasia. The Journal of clinical endocrinology and metabolism. Jul; 2003 88(7): 2993-2998. [PubMed: 12843131]

126. Ogilvie CM, Rumsby G, Kurzawinski T, Conway GS. Outcome of bilateral adrenalectomy in congenital adrenal hyperplasia: one unit's experience. European journal of endocrinology / European Federation of Endocrine Societies. Mar; 2006 154(3):405-408. [PubMed: 16498053]

127. Witchel SF, Miller WL. Prenatal treatment of congenital adrenal hyperplasia-not standard of care. Journal of genetic counseling. Oct; 2012 21(5):615-624. [PubMed: 22639328]

128. Forest MG, Betuel H, David M. Prenatal treatment in congenital adrenal hyperplasia due to 21hydroxylase deficiency: up-date 88 of the French multicentric study. Endocrine research. 1989; 15(1-2):277-301. [PubMed: 2667968]

129. Mercado AB, Wilson RC, Cheng KC, Wei JQ, New MI. Prenatal treatment and diagnosis of congenital adrenal hyperplasia owing to steroid 21-hydroxylase deficiency. The Journal of clinical endocrinology and metabolism. Jul; 1995 80(7):2014-2020. [PubMed: 7608248]

130. Evans MI, Chrousos GP, Mann DW, et al. Pharmacologic suppression of the fetal adrenal gland in utero. Attempted prevention of abnormal external genital masculinization in suspected congenital adrenal hyperplasia. Jama. Feb 15; 1985 253(7):1015-1020. [PubMed: 3968825]

131. David M, Forest MG. Prenatal treatment of congenital adrenal hyperplasia resulting from 21hydroxylase deficiency. The Journal of pediatrics. Nov; 1984 105(5):799-803. [PubMed: 6334149] 
132. New MI, Carlson A, Obeid J, et al. Prenatal diagnosis for congenital adrenal hyperplasia in 532 pregnancies. The Journal of clinical endocrinology and metabolism. Dec; 2001 86(12):56515657. [PubMed: 11739415]

133. New MI, Abraham M, Yuen T, Lekarev O. An update on prenatal diagnosis and treatment of congenital adrenal hyperplasia. Seminars in reproductive medicine. Oct; 2012 30(5):396-399. [PubMed: 23044876]

134. Barinaga M. Technical advances power neuroscience. Science. Nov 16; 1990 250(4983):908909. [PubMed: 2237438]

135. New MI, Tong YK, Yuen T, et al. Noninvasive prenatal diagnosis of congenital adrenal hyperplasia using cell-free fetal DNA in maternal plasma. The Journal of clinical endocrinology and metabolism. Jun; 2014 99(6):E1022-1030. [PubMed: 24606108]

136. Merce Fernandez-Balsells M, Muthusamy K, Smushkin G, et al. Prenatal dexamethasone use for the prevention of virilization in pregnancies at risk for classical congenital adrenal hyperplasia because of 21-hydroxylase (CYP21A2) deficiency: a systematic review and meta-analyses. Clinical endocrinology. Oct; 2010 73(4):436-444. [PubMed: 20550539] 


\section{Key Points}

1. Steroidogenesis in the adrenal gland reflects the zone-specific expression of enzymes, which comprise pathways to efficiently complete the biosynthesis of aldosterone, cortisol, and dehydroepiandrosterone sulfate.

2. The most common form of congenital adrenal hyperplasia is 21-hydroxylase deficiency, in which a block in cortisol biosynthesis shifts precursors to pathways that make excess adrenal-derived androgens.

3. Non-classic 21-hydroxylase deficiency differs from the classic form in that cortisol deficiency and virilization of newborn girls are absent.

4. Treatment for classic 21-hydroxylase deficiency consists of glucocorticoid and mineralocorticoid replacement, and for both classic and non-classic disease, sufficient glucocorticoid is administered to correct the androgen excess.

5. Patients with 21 -hydroxylase deficiency are prone to developing adrenal cortical adenomas and myelolipomas, as well as adrenal rest tumors in the testis or elsewhere. 


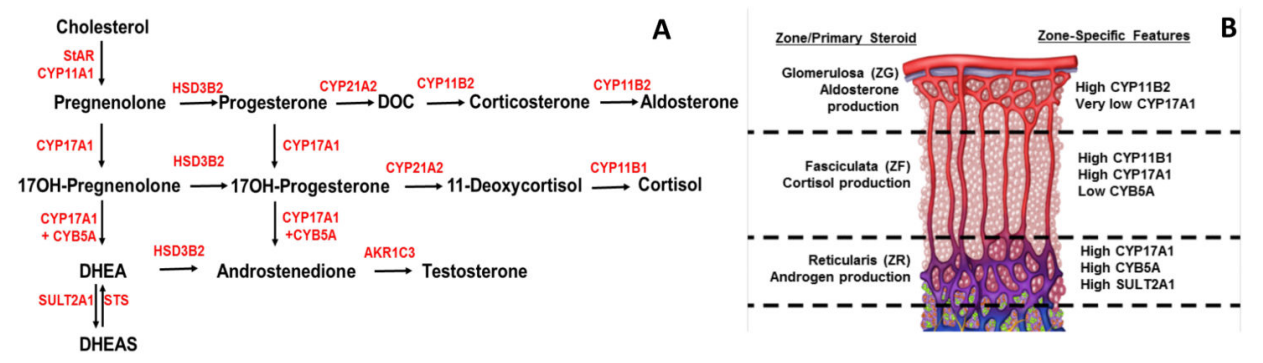

Figure 1.

A. Major adrenal steroid synthesis pathways. B. Adrenal zonation and enzyme expression pattern. StAR, steroidogenic acute regulatory protein; CYP11A1, side-chain cleavage enzyme; HSD3B2, 3 -hydroxysteroid dehydrogenase type 2; CYP21A2, 21-hydroxylase; CYP11B2, aldosterone synthase; CYP17A1, 17a-hydroxylase/17,20-lyase; CYP11B1, 11 $\beta$ hydroxylase; CYB5A, cytochrome $b_{5}$; AKR1C3, 17 $\beta$-hydroxysteroid dehydrogenase type 5; SULTA1/STS, steroid sulfotransferase type $2 \mathrm{~A} 1$. 


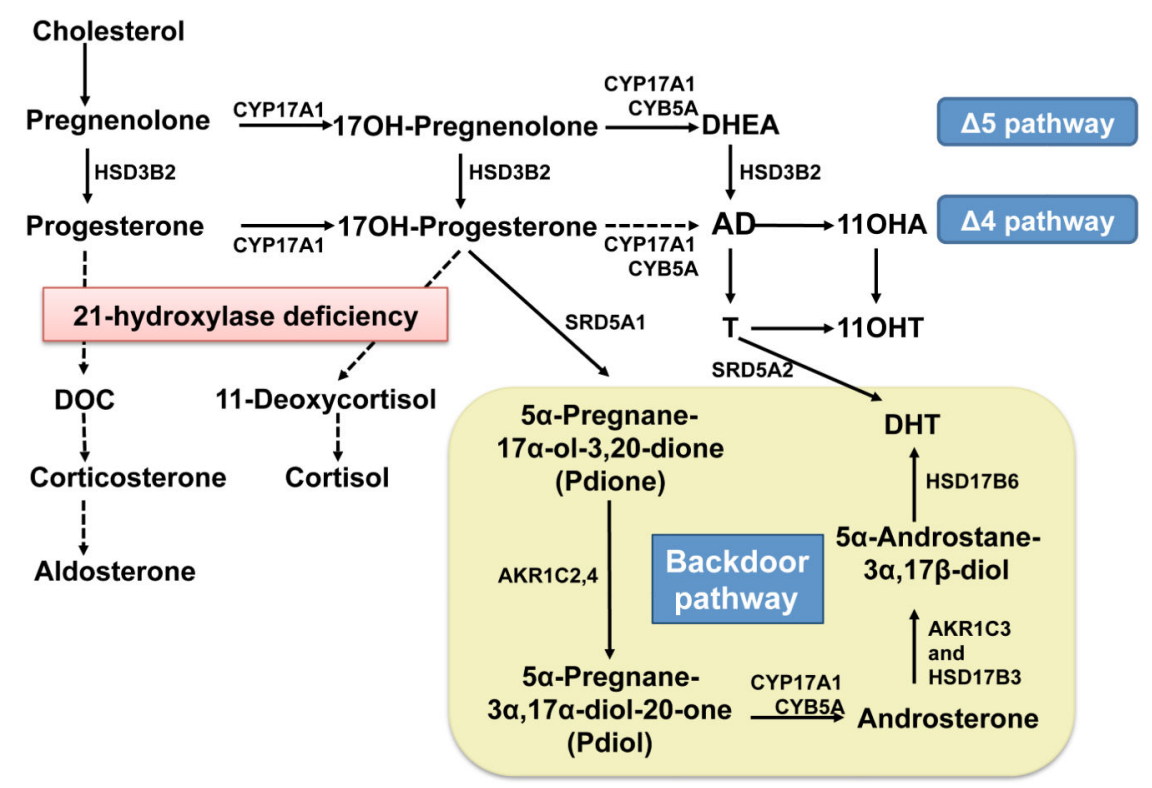

Figure 2.

Pathways of steroid hormone synthesis in 21-hydroxylase deficiency, including backdoor pathway and 11-oxygenated androgens. HSD3B2, 3 $\beta$-hydroxysteroid dehydrogenase type 2; CYP17A1, 17a-hydroxylase/17,20-lyase; CYB5A, cytochrome $b_{5}$; AKR1C3, 17 $\beta$ hydroxysteroid dehydrogenase type 5; AKR1C2,4, aldo-keto reductase types $1 \mathrm{C} 2$ and 1C4; HSD17B6, 17 $\beta$-hydroxysteroid dehydrogenase type 6 (an oxidative 3a-HSD); SRD5A1/2, 5a-reductase, types 1 and 2. 


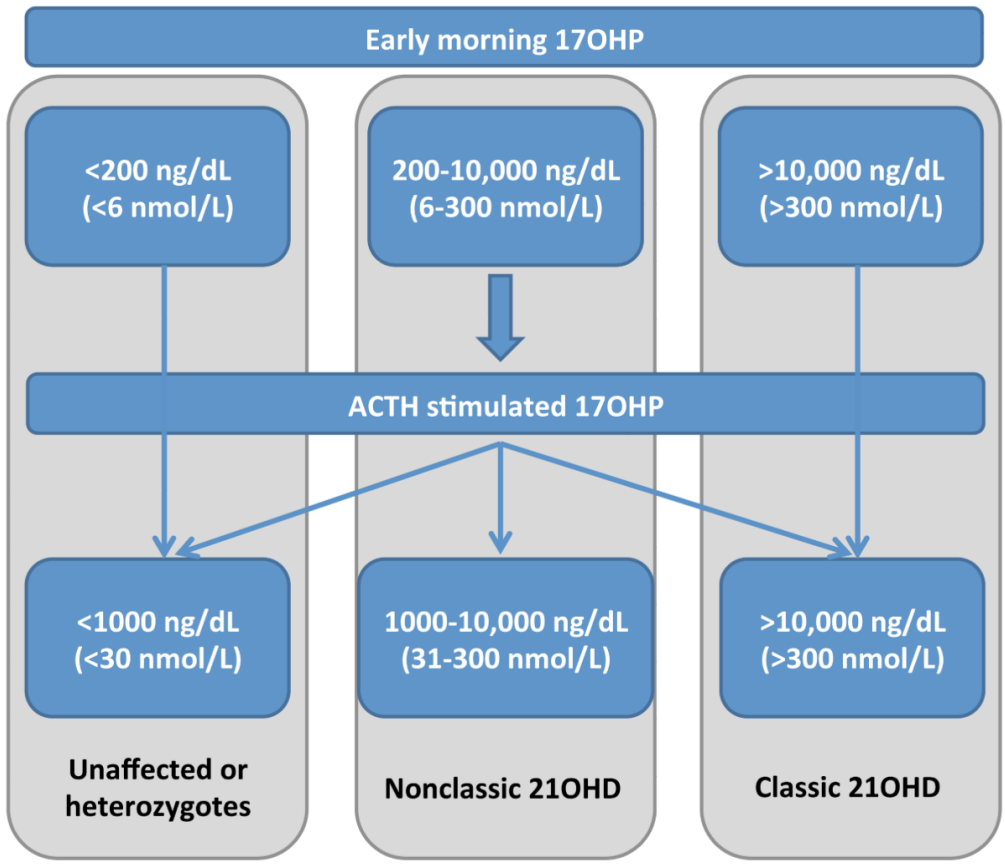

Figure 3.

Schematic evaluation of 21OHD based on baseline and stimulated 17OHP values. 


\section{Normal female}

1

2

3

4

5
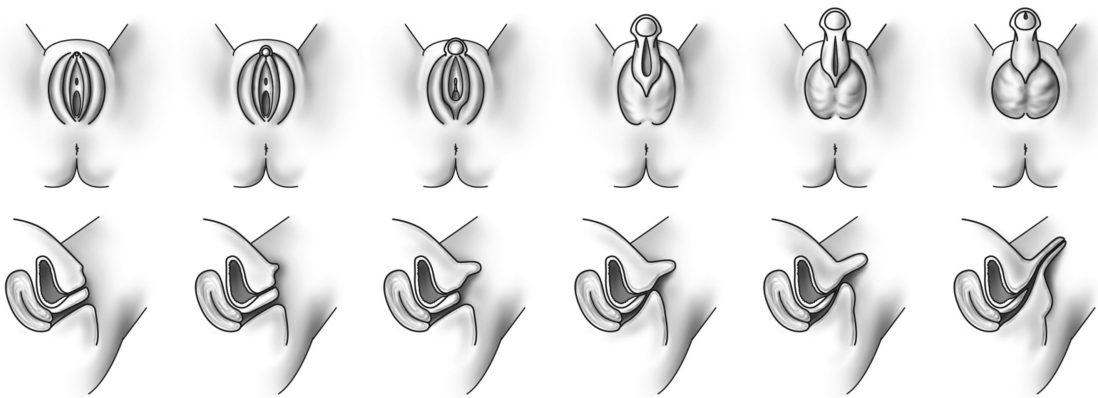

Figure 4.

Prader scale, female external genitalia viewed from above (top) and in cross-section (bottom). 


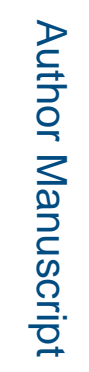

要

D.

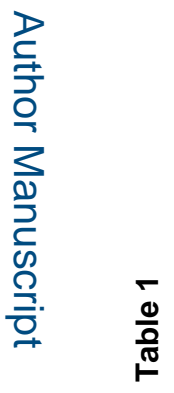

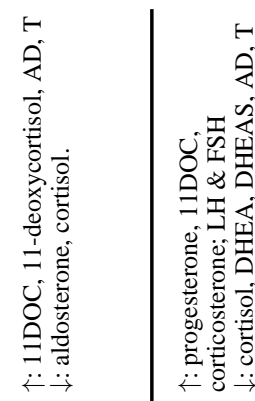

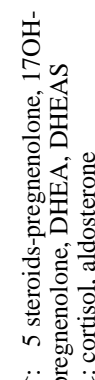

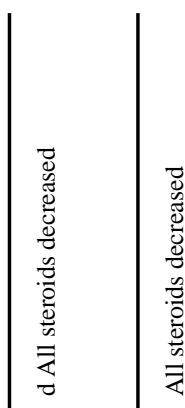

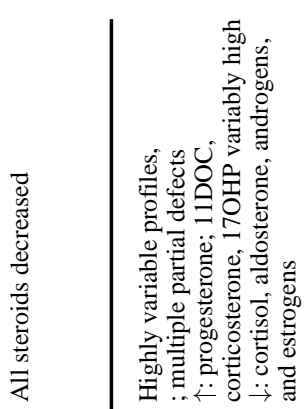

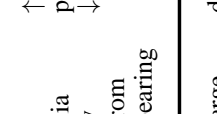

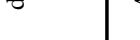

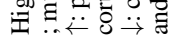

를 을

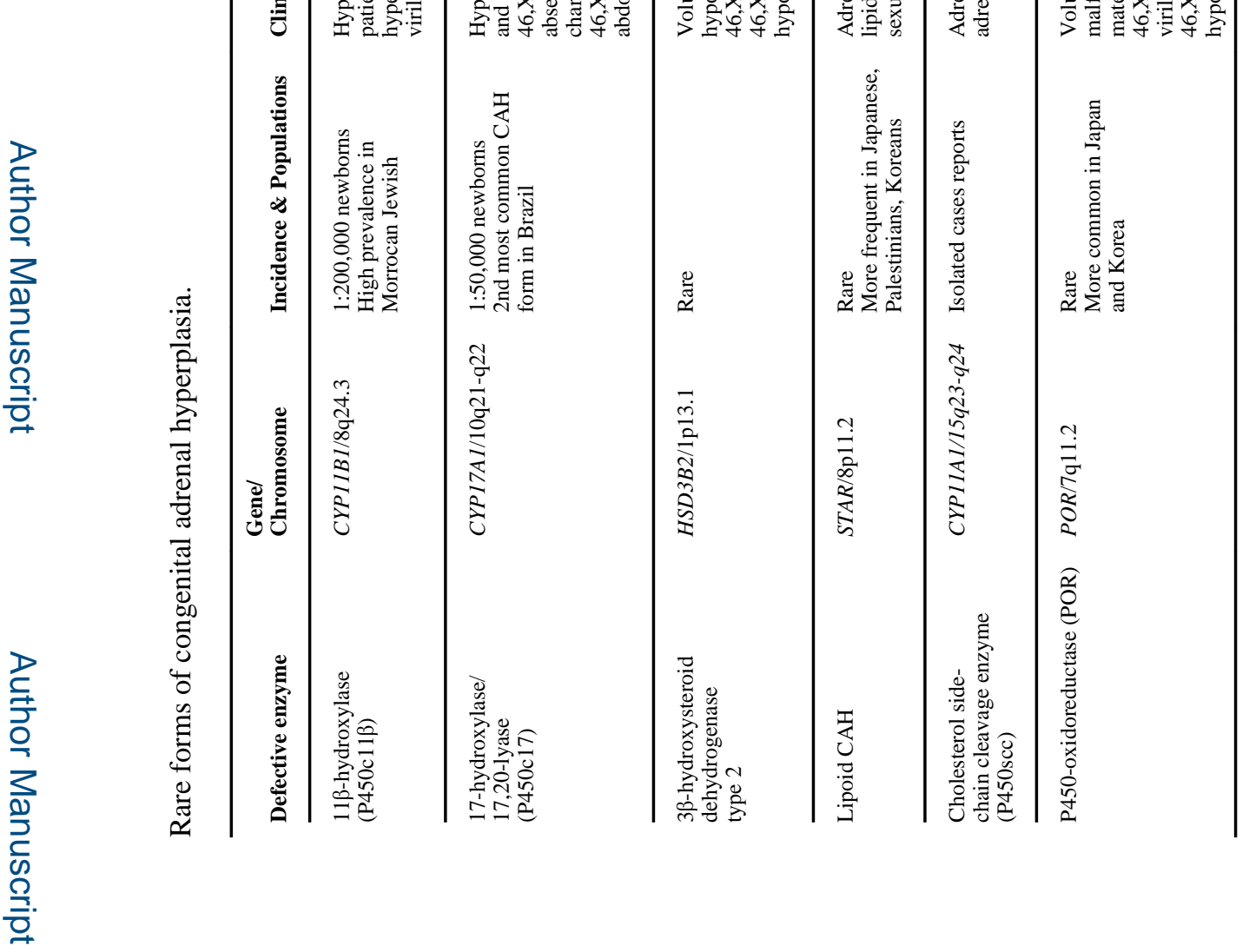

Endocrinol Metab Clin North Am. Author manuscript; available in PMC 2016 June 01. 

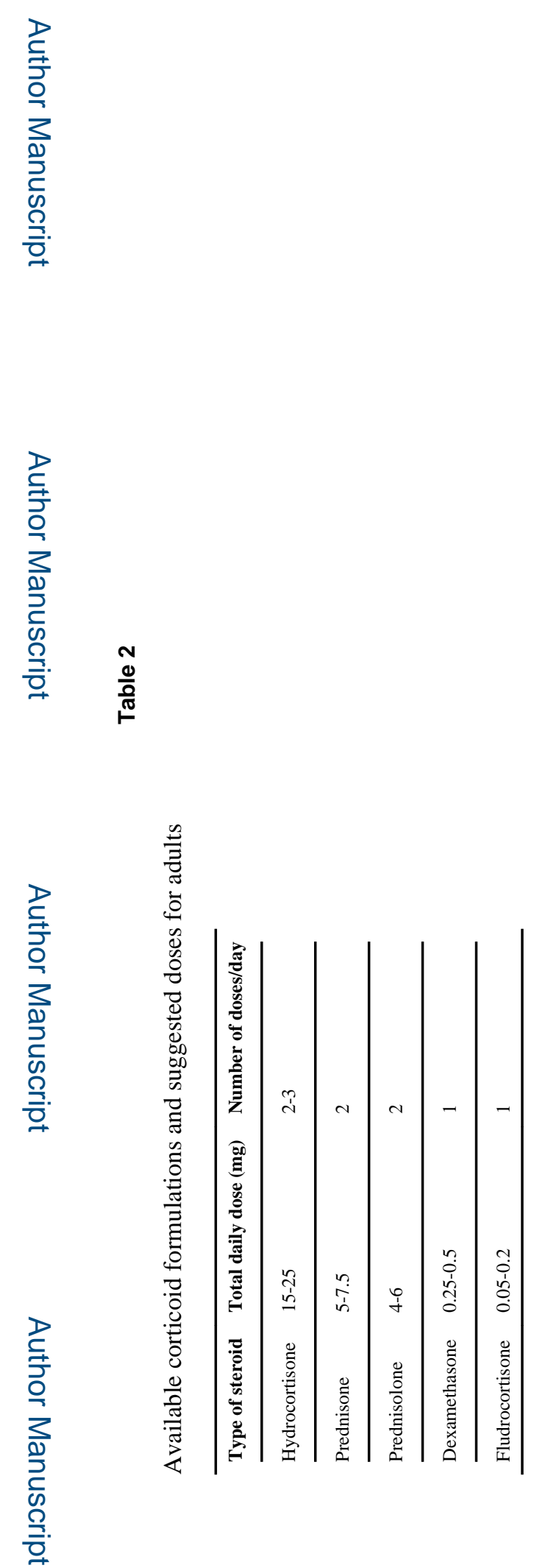

Endocrinol Metab Clin North Am. Author manuscript; available in PMC 2016 June 01. 